\title{
COMBINED 24-HOURS ESOPHAGEAL PH MONITORING AND MULTICHANNEL INTRALUMINAL IMPEDANCE FOR COMPARISON OF GASTROESOPHAGEAL REFLUX IN CHILDREN WITH TYPICAL VERSUS ATYPICAL SYMPTOMS OF GASTROESOPHAGEAL REFLUX DISEASE
}

\author{
Seyed Mohsen DEHGHANI ${ }^{1,2}$, Seyed Alireza TAGHAVI ${ }^{1}$, Hazhir JAVAHERIZADEH ${ }^{3}$ and \\ Maryam NASRI ${ }^{2}$
}

Received 10/10/2015 Accepted 29/3/2016

ABSTRACT - Background - Gastroesophageal reflux disease is the most common esophageal disorder in pediatrics. Objective - The aim of this study was to compare reflux parameters of typical and atypical symptoms of gastroesophageal reflux disease using 24-hour esophageal $\mathrm{pH}$ monitoring and multichannel intraluminal impedance in pediatric population. Methods - In this prospective study, 43 patients aged less than 18 year with suspected gastroesophageal reflux disease were enrolled. The patients were divided into two groups based on the main presenting symptoms (typical versus atypical). Twenty four-hour $\mathrm{pH}$ monitoring and multichannel intraluminal impedance were performed in all the patients for comparing these two group regarding association of symptoms and reflux. Number of refluxes, $\mathrm{pH}$ related reflux, total reflux time, reflux more than 5 minutes, longest time of the reflux, lowest $\mathrm{pH}$ at reflux, reflux index were recorded and compared. Data comparison was done using SPSS Results - The mean age of the patients was $5.7 \pm 3.4$ years and $65.1 \%$ were male. Out of 43 patients 24 cases had typical symptoms and 19 had atypical symptoms. The mean reflux events detected by multichannel intraluminal impedance was more than mean reflux

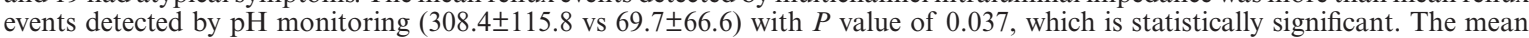
symptom index and symptom association probability were $35.01 \% \pm 20.78 \%$ and $86.42 \% \pm 25.79 \%$, respectively in multichannel intraluminal impedance versus $12.73 \% \pm 12.48 \%$ and $45.16 \% \pm 42.29 \%$ in $\mathrm{pH}$ monitoring $(P$ value $<0.001)$. Number of acid reflux was $46.26 \pm 47.16$ and $30.9 \pm 22.09$ for atypical and typical symptoms respectively. The mean symptom index was $18.12 \% \pm 13.101 \%$ and $8.30 \% \pm 10.301 \%$ in atypical and typical symptoms respectively $(P=0.034)$. Bolus clearance was longer in atypical symptoms compared typical symptoms $(P<0.05)$. Conclusion - Symptom index was significantly higher in atypical symptoms compared to typical symptoms. Higher number of acid reflux was found in children with atypical symptoms of reflux. Longer duration of bolus clearance was found in group with atypical symptoms of reflux.

HEADINGS - Gastroesophageal reflux. Electric impedance. Hydrogen-ion concentration.

\section{INTRODUCTION}

Gastroesophageal reflux is an involuntary passage of gastric contents into the esophagus and can happen several times a day especially after meals ${ }^{(16,19)}$. Most episodes of refluxes are short, asymptomatic and limited to the distal esophagus and happen due to temporary and short-term relaxation of the lower esophageal sphincter ${ }^{(16)}$. Gastroesophageal reflux disease (GERD) is considered if gastroesophageal reflux causes any symptoms or complication.
The diagnosis of GERD in adults is mainly based on clinical history but getting the clinical history for children is difficult especially for infants ${ }^{(10)}$.

Until recently, 24-hour $\mathrm{pH}$ monitoring had long been considered the gold standard for the diagnosis of GERD. This technique has significant limitations as concerns detection of nonacid reflux events (NARE), likely involved in postprandial or atypical extra esophageal manifestations of GERD ${ }^{(12,13)}$.

In infants, in particular nearly $90 \%$ of the reflux events have been reported to be non-acid because of

Declared conflict of interest of all authors: none

Disclosure of funding: no funding received

Limitations: Single center study with small sample size

'Gastroenterohepatology Research Center, Nemazee Teaching Hospital, School of Medicine, Shiraz University of Medical Sciences, Shiraz, Iran; ${ }^{2}$ Department of Pediatrics, Nemazee Teaching Hospital, School of Medicine, Shiraz University of Medical Sciences, Shiraz, Iran; ${ }^{3}$ Nursing Care Research Center in Chronic Diseases and Department of Pediatric Gastroenterology, Ahvaz Jundishapur University of Medical Sciences, Ahvaz, Iran.

Correspondence: Seyed Mohsen Dehghani, Professor of Pediatric Gastroenterology, Gastroenterohepatology Research Center, Nemazee Teaching Hospital, School of Medicine, Shiraz University of Medical Sciences, Shiraz, 71937-11351, Iran. E-mail: dehghanism@sums.ac.ir 
the frequent neutralization of the gastric content following milk or formula feeding ${ }^{(22)}$. Multichannel intraluminal impedance (MII) has recently been introduced as a $\mathrm{pH}$-independent method to investigate the bolus transport in hollow organs. This technique allows detection of reflux events and definition of its chemical (acid, weakly acid, and weakly alkaline) and its physical composition (gas, liquid, or mixed) ${ }^{(17)}$. MII also, defines the proximal extent of the refluxate and the bolus clearance time (BCT) in the esophagus ${ }^{(5)}$.

In adults combined $\mathrm{pH}-\mathrm{MII}$ monitoring has a sensitivity of at least $90 \%$ for the detection of all reflux events ${ }^{(14,17)}$; on the other hand, few data are available in children ${ }^{(11,21)}$. Twenty four-hour $\mathrm{pH}$ monitoring specifies the rate and duration of acid reflux. While MII specifies all the reflux episodes, $\mathrm{pH}$ monitoring is the best method to measure the acid reflux in the esophagus. It also is useful in assessing the effects of therapeutic intervention to reduce esophageal acid ${ }^{(19)}$.

There is limited published paper that compared typical and atypical symptoms of GERD in children using esophageal $\mathrm{pH}$ monitoring and MII. The aim of this study was to compare reflux parameters of typical and atypical symptoms of GERD using esophageal $\mathrm{pH}$ monitoring and MII.

\section{METHODS}

All children with suspected GERD, who were referred consecutively to the Pediatric Gastroenterology Clinic affiliated with Shiraz University of Medical Sciences in 2011, were enrolled to this prospective study. Children aged less than 1 year were not included in our study. Those patients who have taken antacids, $\mathrm{H}_{2}$ receptor blockers, proton pump inhibitors, and prokinetics or patients with other chronic diseases in addition to GERD or threatening respiratory episodes caused by GERD were excluded. Finally, 43 eligible patients were studied. The patients were divided into the typical and atypical groups according to their presenting symptoms. The typical symptoms were included heart burn, regurgitation, vomiting, epigastric pain and other gastrointestinal symptoms and atypical symptoms were included respiratory symptoms, asthma, pneumonia, chronic cough, chest pain, frequent wheezing, hoarseness and non-respiratory cases including lack of weight gain, sleep problems, Sandifer's syndrome and anemia. In atypical cases, patients were evaluated by a pediatric specialist for asthma, allergies, and lung diseases for the presence of respiratory problems and patients with immune system disorders and allergic diseases were excluded from the survey.

All of the patients underwent a 24-hour combined MII$\mathrm{pH}$ monitoring (MMS Company). The height-appropriate catheter was used that containing seven impedance electrodes representing six bipolar impedance channels and a $\mathrm{pH}$-sensitive electrode that set in the middle of the most distal impedance channel. A catheter was placed transnasally into the esophagus approximately 2.5-3 centimeter above the lower esophageal sphincter using $0.87(0.25$ length +5 centimeter) formula. The patients received a regular diet. The parents recorded the time and duration of meal and drink, body position as supine or upright and also time of any symptoms suggesting GERD during monitoring. The reports of $\mathrm{pH}$ sensor and impedance data were generated and automatically analyzed by Ohmega software (MMS).

Acid exposure is expressed as the reflux index (RI, \% time of a $\mathrm{pH}<4$ was measured). A reflux index more than $10.7 \%$ in infants and more than $6 \%$ in children is considered pathological ${ }^{(13)}$.

In analysis of impedance data reflux episodes were classified on the basis of the lowest $\mathrm{pH}$ value as: acid (decreasing $\mathrm{pH}$ to less than or equal to 4), weakly acid ( $\mathrm{pH}$ between 4 and 7), or weakly alkaline ( $\mathrm{pH}$ nadir did not drop below 7) ${ }^{(17)}$.

The liquid reflux episodes are defined when there is more than 50 percent reduction in esophageal impedance from baseline in at least two consecutive channels. Gas or air reflux episodes are defined when a simultaneous increase in impedance more than $3000 \mathrm{ohm}$ is happen in any two consecutive impedance channels with one channel having an absolute value more than $7000 \mathrm{ohm}$. If a reflux episode met both the gas and the liquid criteria it defined as mixed reflux episode ${ }^{(15)}$. The definition of BCT (Bolus Clearance Time) is the time elapsing from a drop in impedance to $50 \%$ of its baseline value, to its recovery (to $50 \%$ ) in the most distal impedance channel. Refluxes were defined as proximal (reaching channels 1 and/or 2), intermediate (reaching channel 3 and/or 4) or distal (reaching channel 5). For each reflux events, its relation to feeding (postprandial time less than or equal to 2 hours) was reported. A pH-only episode was defined as a $\mathrm{pH}$ less than 4 for more than 5 seconds without a retrograde bolus detected by MII monitoring (pH-only reflux events). All of the data were analyzed for all of the patients and for the two groups with typical and atypical symptoms and data have been compared between two study groups.

A symptom was considered associated with an reflux events if it occurred within a 2-minute time window of its onset $^{(7)}$. The symptom index (SI) is define as the number of reflux-associated symptoms/total number of symptoms during 24 hours multiply by 100 and the symptom sensitivity index (SSI) as the number of reflux-associated symptoms/ total number of reflux events in 24 hours multiply by 100 . SI and SSI were calculated for each patient on the basis of the $\mathrm{pH}$ probe alone and on the combined MII-pH results. SI more than or equal to $50 \%$ and SSI more than or equal to $10 \%$ were defined as pathological ${ }^{(1,24)}$.

Symptom association probability (SAP) was defined according to following formula: Dividing 24-hour $\mathrm{pH}$ recording into 2-minute segments.

Each segment was studied whether reflux occurred within it and whether a symptom occurred during the segment. A table with 2 column and two rows was drawn in which the number of 2-minute segments with and without reflux and with and without symptoms were tabulated. The probability of the distribution of symptoms and reflux events in 2-minute windows was then calculated to determine whether it could have occurred by chance. The index was considered positive if $>95 \%$ " ${ }^{(23)}$. 
Written consent was obtained from all of the parents. The study was approved by the local ethics committee of Shiraz University on Medical Sciences.

The data was analyzed by SPSS software version 19.0 and they were compared by Chi-square test, independent t-test and Mann-Whitney test and $p$-values less than 0.05 is statistically significant.

\section{RESULTS}

The mean age of the patients was 5.7 \pm 3.4 year (range, $1-15$ year). Out of 43 patients $28(65.1 \%)$ were boys and 15 $(34.9 \%)$ were girls.

The patients were divided to two groups of typical and atypical according to their presenting symptoms.

The typical group consist of $24(55.8 \%)$ patients with mean age of $5.5 \pm 3.1$ year ( $66.7 \%$ boys), that presented with vomiting $(n=11 ; 45.8 \%)$, regurgitation $(n=8 ; 33.4 \%)$, and heart burn $(\mathrm{n}=5 ; 20.8 \%)$. The atypical group (19 cases; $44.2 \%)$ had a mean age of $5.9 \pm 3.9$ year $(63.1 \%$ boys $)$ and presented with chronic cough $(\mathrm{n}=8 ; 42.2 \%)$, asthma $(\mathrm{n}=5$; $26.4 \%)$, chest pain $(n=2 ; 10.5 \%)$, poor weight gain $(n=2$; $10.5 \%)$, recurrent pneumonia ( $\mathrm{n}=1 ; 5.2 \%)$, and Sandifer's syndrome $(\mathrm{n}=1 ; 5.2 \%)$. The two groups were age $(P=0.38)$ and sex $(P=0.64)$ matched. The mean duration of MII-pH monitoring was $22.26 \pm 1.5$ hours (range; $19.75-25.85$ hour).

The mean number of total reflux events in typical and atypical groups were $58 \pm 43.45$ and $84.47 \pm 86.77$, respectively $(P=0.075)$. Of total 2997 reflux events that detected during $\mathrm{pH}$-monitoring period 1948 (64.9\%) reflux events were $\mathrm{pH}$ related and not associated with a retrograde bolus movement and defined as $\mathrm{pH}$-only reflux events.

The mean of all reflux events during the total $\mathrm{pH}$ recording period were $69.69 \pm 66.61$ (3-380) and the mean of $\mathrm{pH}$-only reflux events was $45.3 \pm 42.9$. In the typical group $67.5 \%$ and in the atypical group $62.7 \%$ of all reflux events were $\mathrm{pH}$-only reflux events $(P=0.65)$.

The mean reflux index in typical and atypical groups were $6.05 \% \pm 10.42 \%$ and $10.42 \% \pm 18.83 \%$, respectively which difference was not significant statistically $(P=0.06)$. The comparison of $\mathrm{pH}$ data analysis between two study groups was shown in Table 1.

TABLE 1. Data analysis about $\mathrm{pH}$ monitoring in typical and atypical patients

\begin{tabular}{lccc}
\hline $\boldsymbol{P}$-value & Atypical $(\mathrm{n}=19)$ & Typical $(\mathrm{n}=24)$ & Items \\
\hline 0.075 & $84.47 \pm 86.77$ & $58 \pm 43.45$ & No. of the refluxes \\
0.076 & $53 \pm 54.08$ & $39.2 \pm 31.6$ & $\mathrm{pH}$ related reflux \\
0.62 & $17.8 \pm 28.5$ & $15.5 \pm 24.9$ & Total reflux times \\
0.32 & $7.52 \pm 13.32$ & $5.95 \pm 9.21$ & Reflux more than 5 minutes \\
0.65 & $43.63 \pm 69.08$ & $48.91 \pm 110.16$ & Longest time of the reflux \\
0.17 & $0.72 \pm 0.83$ & $0.47 \pm 0.47$ & Lowest pH at reflux \\
0.06 & $10.42 \pm 18.83$ & $6.05 \pm 10.42$ & Reflux Index \\
\hline
\end{tabular}

Overall nine (26.5\%) patients had pathologic reflux index, four $(44.4 \%)$ cases in the typical group and five $(55.6 \%)$ cases in the atypical group $(P=0.13)$.

Regarding analysis of MII-pH combined data the mean number of total reflux events was $308.4 \pm 115.8$ (range; 124 668 ) that recorded significantly higher reflux episodes than $\mathrm{pH}$-monitoring alone $(P=0.037)$.

The mean number of reflux events were $81.70 \pm 42.20$ and $88.63 \pm 41.74$ in typical and atypical groups, respectively $(P=0.789)$. The mean number of acid reflux in typical and atypical groups were $30.9 \pm 22.09$ and $46.26 \pm 47.16$ respectively, which difference was significant statistically $(P=0.018)$. There was no statistically significant difference between two study groups regarding the mean number of weakly acid and alkaline reflux events. The comparison between two study groups regarding MII data analysis including weakly acid reflux events, alkaline reflux events, liquid or mixed reflux and extension of reflux are presented in Table 2. There was no statistically significant difference between two study groups regarding type of refluxate (liquid or mixed). Also, the proximal extension of refluxate was not significantly different between two study groups.

In Table 3, SI, SSI and SAP were compared between two groups, only SI in $\mathrm{pH}$-monitoring was significantly different between two groups $(8.30 \% \pm 10.30 \%$ vs $18.12 \% \pm 13.10 \%$; $P=0.034)$.

TABLE 2. Data analysis about MII in typical and atypical patients

\begin{tabular}{lccc}
\hline Items & Typical $(\mathrm{n}=24)$ & Atypical $(\mathrm{n}=19)$ & $\boldsymbol{P}$-value \\
\hline No. of the refluxes & $81.70 \pm 42.20$ & $88.63 \pm 41.74$ & 0.789 \\
Acidic reflux & $30.9 \pm 22.09$ & $46.26 \pm 47.16$ & 0.018 \\
Weak acidic reflux & $42.95 \pm 35.18$ & $36.63 \pm 23.04$ & 0.18 \\
Non-acidic reflux & $8.25 \pm 12.52$ & $5.83 \pm 8.98$ & 0.476 \\
Liquid reflux & $27.83 \pm 22.29$ & $25.63 \pm 15.55$ & 0.527 \\
Mixed reflux & $53.79 \pm 33.78$ & $63 \pm 37.22$ & 0.402 \\
Proximal reflux & $46.50 \pm 29.75$ & $47.15 \pm 24.93$ & 0.314 \\
Middle reflux & $63 \pm 34.18$ & $64.52 \pm 28.58$ & 0.364 \\
Distal reflux & $81.70 \pm 42.20$ & $88.63 \pm 41.74$ & 0.789 \\
\hline
\end{tabular}

TABLE 3. Symptom index, symptom severity index and symptom association probability in different groups and methods

\begin{tabular}{lccc}
\hline $\boldsymbol{P}$-value & Atypical (19) & Typical $(\mathrm{n}=24)$ & Items \\
\hline 0.034 & $18.12 \pm 13.10$ & $8.30 \pm 10.30$ & SI (pH monitoring) $(\%)$ \\
0.667 & $30.87 \pm 17.48$ & $38.41 \pm 23.12$ & SI (MII) $(\%)$ \\
0.617 & $6.19 \pm 6.31$ & $8.62 \pm 13.36$ & SSI (pH monitoring) (\%) \\
0.512 & $8.07 \pm 9.63$ & $9.55 \pm 8.49$ & SSI (MII) $(\%)$ \\
0.127 & $60.48 \pm 36.96$ & $32.54 \pm 43.24$ & SAP (pH monitoring) $(\%)$ \\
0.676 & $81.30 \pm 34.81$ & $90.64 \pm 14.86$ & SAP (MII) $(\%)$ \\
\hline
\end{tabular}

SI: symptom index; SSI: symptom severity index; SAP: symptom association probability. 
Regarding comparison of SI, SSI and SAP between two diagnostic techniques, the mean SI in $\mathrm{pH}$ and MII monitoring were $12.73 \% \pm 12.48 \%$ and $35.01 \% \pm 20.78 \%$, respectively $(P=0.001)$. The mean SAP between two diagnostic methods were also significant statistically $(P=0.001)$ (Table 4$)$.

The bolus clearance time was significantly different between two study groups (Table 5).

TABLE 4. The mean of SI, SSI and SAP in two diagnostic methods

\begin{tabular}{lccc}
\hline $\boldsymbol{P}$-value & MII $(\mathrm{n}=43)$ & $\mathrm{pH}$ monitoring $(\mathrm{n}=43)$ & Items \\
\hline 0.001 & $35.01 \pm 20.78$ & $12.73 \pm 12.48$ & SI $(\%)$ \\
0.285 & $8.88 \pm 8.9$ & $7.52 \pm 10.67$ & SSI (\%) \\
0.001 & $86.42 \pm 25.79$ & $45.16 \pm 42.29$ & SAP $(\%)$ \\
\hline
\end{tabular}

SI: symptom index; SSI: symptom severity index; SAP: symptom association probability.

TABLE 5. Bolus clearance time in different sensors of both groups

\begin{tabular}{lccc}
\hline $\boldsymbol{P}$-value & Atypical $(\mathrm{n}=19)$ & Typical $(\mathrm{n}=24)$ & Bolus Clearance Time $(\mathrm{s})$ \\
\hline 0.03 & $63.50 \pm 24.20$ & $18.27 \pm 10.18$ & channel 1 \\
0.05 & $67.61 \pm 26.81$ & $23.44 \pm 12.94$ & channel 2 \\
0.04 & $70.93 \pm 30.58$ & $25.22 \pm 15.19$ & channel 3 \\
0.03 & $75.76 \pm 35.36$ & $27.12 \pm 17.89$ & channel 4 \\
0.03 & $83.38 \pm 39.33$ & $29.24 \pm 20.23$ & channel 5 \\
0.02 & $99.26 \pm 47.21$ & $32.98 \pm 24.20$ & channel 6 \\
\hline
\end{tabular}

\section{DISCUSSION}

The results of this study revealed that addition of MII to conventional 24-hour $\mathrm{pH}$ monitoring significantly increases the ability of test to determine the association between reflux events and patients symptoms. As the study showed there was an increasing of at least three folds in SI (35.01 versus 12.73; $P=0.001)$ and 2 folds in SAP ( 86.42 versus 45.16 ; $P=0.001)$ comparing between MII and conventional 24-hour $\mathrm{pH}$ monitoring.

Conventional 24-hour $\mathrm{pH}$ monitoring has several shortcomings, mostly related to its inability to detect non-acid reflux events and so underestimating the amount of reflux events. This limitation is particularly important in the postprandial period and in infants, in whom this technique is blind for half the recording time $\mathrm{e}^{(2,20)}$.

Multichannel intraluminal impedance monitoring has recently been described as the only method offering high sensitivity for the detection of all types of reflux events ${ }^{(17)}$. Until now, different criteria to assess the diagnostic accuracy of this technique have been used, the major issue being the inclusion of $\mathrm{pH}$-only reflux events, the clinical significance of which is still debated. The reported prevalence of $\mathrm{pH}$-only reflux events varies between $2 \%$ and $70 \% \%^{(6,14,21,25)}$.
Impedance measures the electrical potential difference within the lumen of the esophagus. Reflux detected by MII does not depend on $\mathrm{pH}$ but in combination with a 24-hour $\mathrm{pH}$ monitoring helps to detect the acid, weakly acid and alkaline reflux. Therefore the combination of impedance and $\mathrm{pH}$ monitoring comparing to $\mathrm{pH}$ monitoring alone shows more reflux episodes ${ }^{(11)}$. About $90 \%$ of reflux episodes in infants are non-acid, because infants are fed frequently and it causes acidic neutralizing of refluxed substances. If a $\mathrm{pH}$ monitoring is done with MII in infants, the sensitivity of test for the diagnosis of reflux often goes up ${ }^{(21)}$. The $\mathrm{pH}$ monitoring limitations include inability to detect non-acid reflux episodes which often happen after meals. Limited sample size in our study may be the cause for some difference in our study compared to other studies.

Francavilla and colleagues studied children suspected of GERD which aimed to evaluate the two diagnostic methods of MII and $\mathrm{pH}$ monitoring for diagnosing of GERD in children. The diagnostic power of combined MII and 24-hour $\mathrm{pH}$ monitoring in detecting all refluxes and acid refluxes in infants were statistically higher than $\mathrm{pH}$ monitoring alone in children older than one year. Adding the MII to 24-hour $\mathrm{pH}$ monitoring method increased the accuracy of the detection of reflux events ${ }^{(4,8)}$. There was a relationship between reflux and atypical symptoms, particularly respiratory ones and also regardless of age and the relationship between reflux and atypical symptoms in infants less than one year of age ${ }^{(5)}$.

In a study done by Wenzl et al, the $\mathrm{pH}$ monitoring and MII were compared in children with GERD. Fifty infants with GERD were studied which results showed that alone $\mathrm{pH}$ monitoring cannot diagnose all reflux episodes in infant but it is useful in diagnosing acidic refluxes and time of acid exposure to esophageal. So, the combination of $\mathrm{pH}$ monitoring method with MII was a valuable diagnostic method in infants with GERD ${ }^{(21)}$.

Another study for evaluation of acid and non-acid reflux episodes by $\mathrm{pH}$ monitoring and MII tests in infants showed that comparing to $\mathrm{pH}$ monitoring, MII shows more reflux episodes especially in non-acid cases $^{(3)}$.

Mattioli and colleagues' were tested $\mathrm{pH}$ monitoring and MII methods on 50 children with GERD ${ }^{(9)}$. According to their findings, acid and non-acid reflux had the same incidence and low rate of clinical symptoms in pediatric group is considered as a limitation of the MII. They suggested further studies on accuracy and precision of $\mathrm{MII}^{(9)}$.

According to our findings, there were no statistically different in terms of demographic characteristics of patients in the two typical and atypical groups. According to the study results, the mean of reflux episodes that were specified by MII methods were more than those specified by $\mathrm{pH}$ monitoring and it can be concluded that adding MII to $\mathrm{pH}$ monitoring leads to more accuracy in diagnosis of reflux in children that is consistent with most studies ${ }^{(3,5,21)}$. Average number of reflux-related to $\mathrm{pH}$ in $\mathrm{pH}$ monitoring test in typical group is more than that in non-typical, but it is not statistically significant that is consistent with previous studies ${ }^{(5)}$. 
One interesting point which is less proven in previous studies is that the number of acid refluxes detected by MII method in atypical group is greater. It shows two points, the first one is that the MII can diagnose more refluxes especially independent ones on $\mathrm{pH}$, the second one is that patients with atypical symptoms have more acid refluxes, so children with atypical reflux symptoms should be treated stronger with regular follow-up period and more frequently to prevent the complications of GERD.

Bolus clearance time difference in various sensors in MII method is greater in atypical group and it is statistically significant that shows the necessity of more attention and treatment in atypical reflux patients. Maybe remaining of the stomach contents in the esophagus for longer time increases the possibility of atypical symptoms for example; possibility for aspiration was more and causes respiratory symptoms.

One of the most recommended applications of $\mathrm{pH}$ monitoring is to confirm the association between a symptom and an reflux event by the calculation of SI, SSI, and $\operatorname{SAP}^{(5)}$.

SI and SAP means were compared in both methods that showed a statistical difference. In fact, there was a greater relationship between disease symptoms and reflux episodes; therefore MII method is superior in detection of association between reflux events and patients symptoms. In the study by Soyer et al. MII can be considered as a superior diagnostic methods in symptomatic children with normal $\mathrm{pH}$ metry findings ${ }^{(18)}$.
This technique has several limitations for routine application in clinical setting. There is no validated data about normal impedance in children. This technique is expensive and time consuming and require well trained personnel. Another therapeutic trial for treatment of acid/nonacid reflux events is mandatory to validate the association of reflux events and symptoms.

As mentioned above SI was significantly higher in atypical symptoms compared to typical symptoms. Higher number of acid reflux was found in children with atypical symptoms of reflux. Longer duration of bolus clearance was found in group with atypical symptoms of reflux. According to these findings, more intense treatment may be required for children with atypical symptoms of GERD. Another study with greater sample size is recommended.

\section{ACKNOWLEDGMENTS}

Data was used in this study was from pediatric residency thesis of Dr. Maryam Nasri and financial support was provided by Shiraz University of Medical Sciences.

\section{Authors' contributions}

Dehghani SM: main idea, data collection and revision of manuscript; Taghavi SA: data collection and writing draft; Nasri M: writing proposal and data collection; Javaherizadeh $\mathrm{H}$ : literature search and revision of manuscript.

Dehghani SM, Taghavi SA, Javaherizadeh H, Nasri M. Monitoramento combinado do pH esofágico e impedância intraluminal multicanal 24 horas para comparação de refluxo gastroesofágico em crianças, com sintomas típicos contra atípicos na doença do refluxo gastroesofágico. Arq Gastroenterol. 2016,53(3):130-5. RESUMO - Contexto - O refluxo gastroesofágico é a doença esofágica mais comum em Pediatria. Objetivo - O objetivo deste estudo foi comparar parâmetros de refluxo em pacientes com sintomas típicos e atípicos de refluxo gastroesofágico na população pediátrica usando impedância intraluminal multicanal e monitoramento 24 horas do $\mathrm{pH}$ esofágico. Métodos - Neste estudo prospectivo, 43 pacientes com idade inferior a 18 anos com suspeita de refluxo gastroesofágico foram observados. Os pacientes foram divididos em dois grupos com base nos principais sintomas de apresentação (típicos versus atípicos). Foram realizados em todos os pacientes, monitoramento de 24 horas do $\mathrm{pH}$ e impedância intraluminal multicanal para comparar esses dois grupos em relação a associação de sintomas e refluxo. Número de refluxos, pH relacionados com refluxo, tempo total de refluxo, refluxo maior do que 5 minutos, tempo mais longo de refluxo, $\mathrm{pH}$ mais baixo no refluxo, índice de refluxo foram registrados e comparados. Comparação de dados foi feita usando SPSS. Resultados - A idade média dos pacientes foi $5.7 \pm 3.4$ anos e $65,1 \%$ eram do sexo masculino. Dos 43 pacientes, 24 tinham sintomas típicos e 19 atípicos. A média de eventos de refluxo detectados por impedância intraluminal multicanal foi maior do que a detectada pelo monitoramento do $\mathrm{pH}(308.4 \pm 115.8$ vs $69.7 \pm 66.6)$ com $P=0,037$, que é estatisticamente significativo. O índice médio de sintoma e a probabilidade de associação do sintoma foram $35.01 \% \pm 20.78 \%$ e $86.42 \% \pm 25.79 \%$, respectivamente em impedância intraluminal multicanal contra $12,73 \% \pm 12,48 \%$ e $45 \% \pm 42,29 \%$ em monitoramento do $\mathrm{pH}$ ( $P$ valor \&lt; 0,001$)$. O número de refluxos ácidos foi 46,26 $\pm 47,16$ e 30,9 $\pm 22,09$ para sintomas típicos e atípicos, respectivamente. O índice médio de sintoma foi de $18,12 \% \pm 13,101 \%$ e $8,30 \% \pm 10,301 \%$ em sintomas típicos e atípicos em respectivamente $P=0,034)$. A limpeza do bolus foi maior no grupo de sintomas atípicos quando comparados a sintomas típicos. $(P<0,05)$ Conclusão - O Índice de sintoma foi significativamente maior nos pacientes com sintomas atípicos em comparação com os de sintomas típicos. Maior número de refluxos ácidos foi encontrado em crianças com sintomas atípicos de refluxo. Maior duração da limpeza do bolus foi encontrada no grupo com sintomas atípicos de refluxo.

DESCRITORES - Refluxo gastroesofágico. Impedância elétrica. Concentração de íons de Hidrogênio. 


\section{REFERENCES}

1. Breumelhof R, Smout AJ. The symptom sensitivity index: a valuable additional parameter in 24-hour esophageal $\mathrm{pH}$ recording. Am J Gastroenterol. 1991,86:160-4.

2. Condino AA, Sondheimer J, Pan Z, Gralla J, Perry D, O'Connor JA. Evaluation of gastroesophageal reflux in pediatric patients with asthma using impedance-pH monitoring. J Pediatr. 2006,149:216-9.

3. Condino AA, Sondheimer J, Pan Z, Gralla J, Perry D, O’Connor JA. Evaluation of infantile acid and nonacid gastroesophageal reflux using combined $\mathrm{pH}$ monitoring and impedance measurement. J Pediatr Gastroenterol Nutr. 2006,42:16-21.

4. Cresi F, Locatelli E, Marinaccio C, Grasso G, Coscia A, Bertino E. Prognostic values of multichannel intraluminal impedance and $\mathrm{pH}$ monitoring in newborns with symptoms of gastroesophageal reflux disease. J Pediatr. 2013,162:770-5.

5. Francavilla R, Magista AM, Bucci N, Villirillo A, Boscarelli G, Mappa L, et al. Comparison of esophageal $\mathrm{pH}$ and multichannel intraluminal impedance testing in pediatric patients with suspected gastroesophageal reflux. J Pediatr Gastroenterol Nutr. 2010,50:154-60.

6. Hila A, Agrawal A, Castell DO. Combined multichannel intraluminal impedance and $\mathrm{pH}$ esophageal testing compared to $\mathrm{pH}$ alone for diagnosing both acid and weakly acidic gastroesophageal reflux. Clin Gastroenterol Hepatol. 2007,5:172-7.

7. Lam HG, Breumelhof R, Roelofs JM, Van Berge Henegouwen GP, Smout AJ. What is the optimal time window in symptom analysis of 24-hour esophageal pressure and pH data? Dig Dis Sci. 1994,39:402-9.

8. Masiak W, Wallner G, Wallner J, Pedowski T, Solecki M. Combined esophagea multichannel intraluminal impedance and $\mathrm{pH}$ monitoring $(\mathrm{MII}-\mathrm{pH})$ in the diagnostics and treatment of gastroesophageal reflux disease and its complications. Pol Przegl Chir. 2011,83:488-96.

9. Mattioli G, Pini-Prato A, Gentilino V, Caponcelli E, Avanzini S, Parodi S, et al Esophageal impedance/pH monitoring in pediatric patients: preliminary experience with 50 cases. Dig Dis Sci. 2006,51:2341-7.

10. Orenstein SR, Cohn JF, Shalaby TM, Kartan R. Reliability and validity of an infant gastroesophageal reflux questionnaire. Clin Pediatr (Phila). 1993,32:472-84.

11. Rosen R, Lord C, Nurko S. The sensitivity of multichannel intraluminal impedance and the $\mathrm{pH}$ probe in the evaluation of gastroesophageal reflux in children. Clin Gastroenterol Hepatol. 2006,4:167-72.

12. Rudolph CD. Supraesophageal complications of gastroesophageal reflux in children: challenges in diagnosis and treatment. Am J Med. 2003,115 Suppl 3A:150s-156s.

13. Rudolph CD, Mazur LJ, Liptak GS, Baker RD, Boyle JT, Colletti RB, et al. Guidelines for evaluation and treatment of gastroesophageal reflux in infants and children: recommendations of the North American Society for Pediatric Gastroenterology and Nutrition. J Pediatr Gastroenterol Nutr. 2001,32 Suppl 2:S1-31.
14. Shay S, Richter J. Direct comparison of impedance, manometry, and $\mathrm{pH}$ Probe in detecting reflux before and after a meal. Dig Dis Sci. 2005,50:1584-90.

15. Shay S, Tutuian R, Sifrim D, Vela M, Wise J, Balaji N, et al. Twenty-four hour ambulatory simultaneous impedance and $\mathrm{pH}$ monitoring: a multicenter report of normal values from 60 healthy volunteers. Am J Gastroenterol. 2004,99:1037-43.

16. Sherman PM, Hassall E, Fagundes-Neto U, Gold BD, Kato S, Koletzko S, et al. A global, evidence-based consensus on the definition of gastroesophageal reflux disease in the pediatric population. Am J Gastroenterol. 2009,104:1278-95; quiz 1296.

17. Sifrim D, Castell D, Dent J, Kahrilas PJ. Gastro-oesophageal reflux monitoring: review and consensus report on detection and definitions of acid, non-acid, and gas reflux. Gut. 2004,53:1024-31.

18. Soyer T, Gulerman F, Boybeyi O, Aslan M, Gunal Y. Results of multichannel intraluminal impedance $\mathrm{pH}$ metry in symptomathic children with normal $\mathrm{pH}$ metry findings. Eur J Pediatr Surg. 2014,24:514-8.

19. Vandenplas Y, Rudolph CD, Di Lorenzo C, Hassall E, Liptak G, Mazur L, et al. Pediatric gastroesophageal reflux clinical practice guidelines: joint recommendations of the North American Society for Pediatric Gastroenterology, Hepatology, and Nutrition (NASPGHAN) and the European Society for Pediatric Gastroenterology, Hepatology, and Nutrition (ESPGHAN). J Pediatr Gastroenterol Nutr. 2009,49:498-547.

20. Washington N, Spensley PJ, Smith CA, Parker M, Bush D, Jackson SJ, et al. Dual $\mathrm{pH}$ probe monitoring versus single $\mathrm{pH}$ probe monitoring in infants on milk feeds: the impact on diagnosis. Arch Dis Child. 1999,81:309-12.

21. Wenzl TG, Moroder C, Trachterna M, Thomson M, Silny J, Heimann G, et al. Esophageal $\mathrm{pH}$ monitoring and impedance measurement: a comparison of two diagnostic tests for gastroesophageal reflux. J Pediatr Gastroenterol Nutr. 2002,34:519-23.

22. Wenzl TG, Silny J, Schenke S, Peschgens T, Heimann G, Skopnik H. Gastroesophageal reflux and respiratory phenomena in infants: status of the intraluminal impedance technique. J Pediatr Gastroenterol Nutr. 1999,28:423-8.

23. Weusten BL, Roelofs JM, Akkermans LM, Van Berge-Henegouwen GP, Smout AJ. The symptom-association probability: an improved method for symptom analysis of 24-hour esophageal $\mathrm{pH}$ data. Gastroenterology. 1994,107:1741-5.

24. Wiener GJ, Richter JE, Copper JB, Wu WC, Castell DO. The symptom index: a clinically important parameter of ambulatory 24 -hour esophageal $\mathrm{pH}$ monitoring. Am J Gastroenterol. 1988,83:358-61.

25. Woodley FW, Mousa H. Acid gastroesophageal reflux reports in infants: a comparison of esophageal $\mathrm{pH}$ monitoring and multichannel intraluminal impedance measurements. Dig Dis Sci. 2006,51:1910-6. 